\title{
Multi-level analysis of electronic health record adoption by health care professionals: A study protocol
}

Marie-Pierre Gagnon*1,2, Mathieu Ouimet1,3, Gaston Godin², Michel Rousseau4, Michel Labrecque 1,4, Yvan Leduc and Anis Ben Abdeljelil1

\begin{abstract}
Background: The electronic health record (EHR) is an important application of information and communication technologies to the healthcare sector. EHR implementation is expected to produce benefits for patients, professionals, organisations, and the population as a whole. These benefits cannot be achieved without the adoption of EHR by healthcare professionals. Nevertheless, the influence of individual and organisational factors in determining EHR adoption is still unclear. This study aims to assess the unique contribution of individual and organisational factors on EHR adoption in healthcare settings, as well as possible interrelations between these factors.

Methods: A prospective study will be conducted. A stratified random sampling method will be used to select 50 healthcare organisations in the Quebec City Health Region (Canada). At the individual level, a sample of 15 to 30 health professionals will be chosen within each organisation depending on its size. A semi-structured questionnaire will be administered to two key informants in each organisation to collect organisational data. A composite adoption score of EHR adoption will be developed based on a Delphi process and will be used as the outcome variable. Twelve to eighteen months after the first contact, depending on the pace of EHR implementation, key informants and clinicians will be contacted once again to monitor the evolution of EHR adoption. A multilevel regression model will be applied to identify the organisational and individual determinants of EHR adoption in clinical settings. Alternative analytical models would be applied if necessary.
\end{abstract}

Results: The study will assess the contribution of organisational and individual factors, as well as their interactions, to the implementation of EHR in clinical settings.

Conclusions: These results will be very relevant for decision makers and managers who are facing the challenge of implementing EHR in the healthcare system. In addition, this research constitutes a major contribution to the field of knowledge transfer and implementation science.

\section{Background}

Information and communication technologies (ICTs) include a set of effective tools to collect, store, process, and exchange health-related information [1]. In that respect, it is believed that ICT could improve safety, quality, and cost-efficiency of healthcare services. Among the applications of ICTs to the healthcare sector, the electronic health record (EHR) is viewed as the backbone

\footnotetext{
* Correspondence: Marie-pierre.gagnon@fsi.ulaval.ca

1 Research Center of the Centre Hospitalier Universitaire de Québec, Québec, Canada

Full list of author information is available at the end of the article
}

supporting the integration of various tools (e.g., emergency information, test ordering, electronic prescription, decision-support systems, digital imagery, and telemedicine) that could improve the uptake of evidence into clinical decisions. Using such evidence in daily clinical practices could enable a safer and more efficient healthcare system [2,3].

Patients, professionals, organisations, and the public in general are thus expected to benefit from EHR implementation. International literature supports several benefits of EHRs for patients [4-11]. One of the main benefits reported is the increased quality of care resulting from 
patients having their essential health data accessible to their different providers $[11,12]$. Based on relevant disease management programs [10,13], EHR could support empowered citizens to actively take part in decisions regarding their health. The EHR is also a tool that facilitates knowledge exchange and decision making among healthcare professionals by providing them with relevant, timely, and up-to-date information [14-16].

\section{Current knowledge on EHR adoption}

The implementation of EHR in healthcare systems is currently supported in many countries. In the US, the Institute of Medicine has qualified the EHR as 'an essential technology for healthcare' [17]. The development of a National Health Information Infrastructure (NHII) was then seen as the core for the implementation of EHR across the US [18]. However, the rate of EHR adoption by office physicians remains slow in this country [19]. The UK has launched its National Program for Information Technology (NPfIT), an initiative from the National Health Service (NHS) to move towards an electronic care record for patients and to connect general practitioner and hospitals. However, this strategy has not yet reached the expected adoption levels [20-23].

An increasing body of knowledge on EHR implementation shows that a majority of projects do not sustain over the experimentation phase [24,25]. Issues associated with the slow diffusion of the EHR include: important start-up investments, lack of financial incentives, uncertain payoffs, suboptimal technology, low priority, and resistance of potential users [26-28]. A comparative study of EHR adoption among general practitioners (GPs) in 10 countries showed that Canadian GPs ranked last [29]. Another study of EHR adoption by primary care physicians showed that only $23 \%$ of them were using the EHR in Canada, compared to $89 \%$ in the UK [30]. Also, perceptions towards the use of EHR may vary between health professionals groups, adding to the complexity of implementing this technology in a pluralist healthcare system [31]. Thus, understanding factors influencing EHR adoption is one of the key to ensure its optimal integration and, ultimately, benefits measurement within health system and population. Factors pertaining to users and their working environment have to be considered because many previous EHR projects have failed due to the lack of integration into practices and organisations [32,33].

Previous studies on factors affecting EHR adoption in healthcare settings have traditionally focused on a single aspect of this multidimensional phenomenon [31]. As such, studies have usually assessed the adoption determinants either at the organisational/systemic level or at the professional/individual level. With regard to individual factors, several studies on barriers and facilitators to physicians' EHR adoption have been conducted [34-37].
Other studies have explored factors associated with nurses' intention to adopt EHR [38,39]. Factors affecting the readiness of healthcare organisations to implement interoperable information systems have also been studied [40-42].

Other studies have explored EHR adoption determinants at different levels without considering their possible interdependence. For example, Simon et al. $[19,25]$ have conducted a survey on EHR adoption by medical practices in Massachusetts exploring organisational, professional, and technological factors. Their results showed that larger practices (seven physicians or more), hospitalsetting and teaching status were significant predictors of EHR adoption. However, EHR adoption by healthcare professionals working in a specific setting might be influenced by the characteristics of the organisation, which implies a hierarchical or clustered data structure.

In Quebec, Lapointe [31,43] conducted a multidimensional analysis on the adoption of hospital information system by nurses and physicians using a multiple case study. Her findings indicate that individual decision to adopt the system or not may conflict with the organisation's decision to implement this system. This study also supports the hypothesis that organisational, group, and individual factors all influence the adoption of information systems to various degrees. Nevertheless, to the best of our knowledge, possible interactions between factors influencing EHR adoption by specific groups of professionals at different levels have never been assessed quantitatively.

\section{Goal and objectives}

Adoption of EHR by healthcare professionals is an essential condition to ensure that its expected benefits will materialise. However, there is a gap in knowledge regarding the specific influence of individual and organisational factors in determining EHR adoption. The aim of this study is thus to assess the unique contribution of individual and organisational factors on the adoption of EHR in healthcare settings, as well as possible interrelations between these factors.

Specifically, the study seeks to answer the following questions: which factors, at the individual and organisational levels (independent variables) predict EHR adoption by healthcare professionals (dependant variable)?; what are the unique contributions of individual and organisational factors in predicting EHR adoption?; and how are individual and organisational adoption factors interrelated?

\section{Theoretical frameworks of EHR adoption}

The phenomenon of innovation is omnipresent in the healthcare system where new technologies and interventions are constantly introduced in order to improve the 
health of individuals and populations. Innovation can be studied at four distinct levels: the individual healthcare professionals; the healthcare professionals groups; the healthcare organisations; and the larger healthcare system [44]. Several theories can be used to explore the adoption of innovations at each of these levels. However, it is important to select theories according to a set of attributes, such as their predictive or explicative effectiveness and their ability to provide targets for intervention [45].

\section{Organisational factors}

Many theoretical models have been used to investigate the organisational characteristics influencing technology adoption. Given the particular nature of healthcare organisations, Mintzberg's configuration theory [46] and the neo-institutional theory [47-49] propose relevant concepts to analyse the relationships between hospitals' characteristics and the adoption of information and communication technologies [31].

The organisational theoretical framework guiding this study results from literature reviews and empirical studies, coupled with the characteristics proposed in Mintzberg's configuration theory [46]. The structural components of the professional bureaucracy--the type of configuration usually found in healthcare organisations-are defined in Table 1. Concepts pertaining to the context in which a new technology is introduced, inspired by the neo-institutional theory $[47,48]$, are also included in the framework. Furthermore, based upon results from previous studies [31,50-53], research hypotheses on the expected influence of each structural and contextual variable on EHR adoption are presented.

\section{Individual factors}

Several theoretical models can be applied to study EHR adoption by healthcare professionals. Most of them consist in frameworks developed in other scientific fields, such as psychology, education, and sociology. In this study, factors that are hypothesised to influence EHR adoption by individual healthcare professionals are borrowed from a set of validated theoretical frameworks.

\section{Diffusion of innovation}

Among those frameworks, the Diffusion of Innovation (DOI) has received much attention in the study of ICT adoption in healthcare [54]. This model suggests that there are three main sources influencing the adoption and diffusion of an innovation, namely perceptions of innovation characteristics, characteristics of the adopter, and contextual factors [55]. This model has been applied to study the adoption of various information technologies in healthcare [39]. However, the DOI does not provide information on how to assess innovation characteristics.
Furthermore, this model has been criticized for its lack of specificity [56].

\section{Technology acceptance model}

The Technology Acceptance Model (TAM) [57] was specifically developed to understand user's acceptance of information technology. In its original version, the TAM is similar to the Theory of Reasoned Action [58], considering intention as the direct antecedent of behaviour, while attitude and social norms being the predictors of intention [57]. The particularity of the TAM is that it decomposes the attitudinal construct found in previous models into two distinct factors--perceived ease of use (PEU) and perceived usefulness (PU). However, the TAM has been simplified over time and the attitudinal and normative components have been dropped from the model, leaving PEU and PU as the sole predictors of intention [59]. Many studies have empirically tested the TAM for the prediction of adoption behaviours for various technologies, including healthcare professionals' acceptance of telemedicine $[60,61]$ and computerized decision-support system [62].

The TAM was specifically developed in the field of ICT adoption and it proposes a set of constructs that can be measured among various groups of users [57]. One limitation of this model is that it does not consider the social environment in which the technology is introduced. Consequently, some authors have questioned its applicability to study healthcare professionals' behaviours [60]. Various efforts have been made to extend the TAM by either introducing variables from other theoretical models or by examining antecedents and moderators of perceived ease of use and perceived usefulness.

\section{Theories of reasoned action and planned behaviour}

These two models are presented jointly because the Theory of Planned Behaviour (TPB) [63,64] constitutes an extension to the Theory of Reasoned Action (TRA) [58]. Both models were developed in the field of social psychology in order to understand a variety of human behaviours. The TRA [58] postulates that the realisation of a given behaviour (B) is predicted by the individual intention (I) to perform this behaviour. In turn, the individual intention is formed by two antecedents--attitude toward act or behaviour (AACT) and subjective norm (SN). AACT represents the evaluation of the advantages and disadvantages associated with the performance of a given behaviour, weighted by their relative importance. $\mathrm{SN}$ is the individual's perception that significant others will approve or disapprove the behaviour in question, weighted by individual's motivation to comply.

However, some behaviour might not be totally under volitional control, which means that they require specific resources, skills, or opportunities for an individual in 
Table 1: Structural and contextual variables and their expected influence on EHR adoption

\begin{tabular}{|c|c|c|}
\hline Variable & Description & Hypothesis \\
\hline Horizontal specialisation & $\begin{array}{l}\text { The division of work is negotiated } \\
\text { between the various specialties rather } \\
\text { than on a hierarchical basis. }\end{array}$ & $\begin{array}{l}\text { 1. Horizontal specialisation has a negative } \\
\text { influence on EHR adoption. }\end{array}$ \\
\hline Functional differentiation & $\begin{array}{l}\text { Differentiation, i.e., how the work is } \\
\text { divided, is based upon production units, or } \\
\text { fields of expertise. }\end{array}$ & $\begin{array}{l}\text { 2. The influence of functional } \\
\text { differentiation on EHR adoption depends } \\
\text { on groups' values towards the system. }\end{array}$ \\
\hline Decentralisation of power & $\begin{array}{l}\text { Informal power is both vertically and } \\
\text { horizontally decentralised. Power is } \\
\text { dispersed towards the bottom of the } \\
\text { hierarchical chain and professionals exert a } \\
\text { control over decision processes. }\end{array}$ & $\begin{array}{l}\text { 3. Decentralisation of power has a variable } \\
\text { influence on EHR adoption, depending on } \\
\text { professionals' values towards the } \\
\text { technology. }\end{array}$ \\
\hline Size & $\begin{array}{l}\text { Hospital size has usually been measured as } \\
\text { the number of beds. In the case of other } \\
\text { organisations, number of physicians. }\end{array}$ & $\begin{array}{l}\text { 4. Larger organisations are more likely to } \\
\text { adopt EHR. }\end{array}$ \\
\hline Competition & $\begin{array}{l}\text { The number of hospitals in the health } \\
\text { region. }\end{array}$ & $\begin{array}{l}\text { 5. Organisations in regions where there are } \\
\text { other hospitals are more likely to adopt } \\
\text { HER. }\end{array}$ \\
\hline Localisation & $\begin{array}{l}\text { Health care organisations in the Province } \\
\text { of Quebec are located in urban, outlying, } \\
\text { remote, or isolated regions. }\end{array}$ & $\begin{array}{l}\text { 6. Organisations located in remote and } \\
\text { isolated regions are less likely to adopt } \\
\text { EHR. }\end{array}$ \\
\hline Teaching status & $\begin{array}{l}\text { Organisations with a teaching status have } \\
\text { a larger network because of the presence } \\
\text { physicians and residents from university } \\
\text { hospitals. }\end{array}$ & $\begin{array}{l}\text { 7. Organisations with a teaching status are } \\
\text { more likely to adopt EHR. }\end{array}$ \\
\hline
\end{tabular}

order to perform them. Therefore, the TPB [63,64] proposes to add the perception of behavioural control (PBC)--the person's evaluation of the barriers related to the realisation of the behaviour and his or her perceived capacity to overcome them--as a direct determinant of the behaviour. Furthermore, the PBC can also act as an indirect determinant of the behaviour by influencing the intention. According to these models, the influence of external variables, such as age, gender, and personality traits, is usually mediated through theoretical constructs. Both the TRA and the TPB have shown good predictive validity to explain behaviour and behavioural intention [65]. Moreover, these theories have been successful in explaining different behaviours of healthcare professionals [66-70]. However, evidence shows that the correlation between behavioural intention and actual behaviour is usually small to moderate $[65,71]$. A meta-analysis of the intention-behaviour relation among healthcare professionals [72] has reported significant positive correlations between intention and self-reported behaviour. A recent systematic review of the application of social cognitive theories to understand healthcare professionals' intentions and behaviours also supports these models [70].

\section{Theory of interpersonal behaviour}

Another model that has been used to understand acceptance behaviours with respect to ICT is the Theory of Interpersonal Behaviour (TIB) [73]. In essence, the TIB is similar to the other intention-behaviour models in that it also proposes a set of psychosocial factors that influence the realisation of a given behaviour. However, the TIB specifies that three direct determinants influence behaviour: intention, facilitating conditions, and habit. Intention refers to the individual's motivation regarding the performance of a given behaviour. Facilitating conditions represent perceived factors in the environment that can ease the realization of a given behaviour. Habit constitutes the level of 'routinisation' of a given behaviour, i.e., the frequency of its occurrence.

According to the TIB, the behavioural intention is formed by attitudinal normative beliefs. Attitudinal beliefs are formed by affective (affect) and cognitive (per- 
ceived consequences) dimensions. Affect represents an emotional state that the performance of a given behaviour evokes for an individual, whereas perceived consequences refer to the cognitive evaluation of the probable consequences of the behaviour. The TIB also incorporates two normative dimensions: social and personal norms. Social norms are composed by normative and role beliefs. Normative beliefs consist of the internalisation by an individual of referent people or groups' opinion about the realisation of the behaviour, whereas role beliefs reflect the extent to which an individual thinks someone of his or her age, gender and social position should or should not behave. The personal normative construct of the TIB is formed by personal normative belief, described as the feeling of personal obligation regarding the performance of a given behaviour, and self-identity, which refers to the degree of congruence between the individual's perception of self and the characteristics he or she associates with the realisation of the behaviour.

Compared to other intention-behaviour models, the TIB has a wider scope because it also considers cultural, social, and moral factors. The TIB was found to be a successful model to explain healthcare professionals' intention to perform clinical behaviours [70]. The TIB is also sensitive to cultural variations that affect the realisation of behaviours within specific social groups, such as healthcare professionals [74]. An integrative theoretical framework (Figure 1) will be used to assess factors influencing EHR adoption at the individual level based on the literature and previous research on healthcare professionals' behaviours conducted by the research team $[66,67,75-77]$. This framework comprises variables from the TPB and the TIB and has been applied in previous similar research $[75,77]$.

\section{Methods Study design}

A prospective cohort study will be used to identify the individual and organisational determinants of EHR adoption by healthcare professionals. This prospective design will follow study participants over time to verify how the determinants of EHR adoption evolve and to allow testing the predictive validity of the theoretical framework. Using Hierarchical Linear Model (HLM), the study will take into account the nested structure of data [78]. If no significant variation in the dependant variable (EHR adoption) is found across organisational units, then alternative analytical models would be applied.

\section{Population and settings}

A stratified random sample of 50 healthcare organisations (HCOs) will be selected in the Capitale Nationale Health Region (Quebec City Health Region). This health region is divided into four Health and Social Services
Centres (CSSS) that integrate a total of 78 units. The health region also includes 17 accredited Family Physicians Groups (FMGs). For the purpose of the study, a healthcare organisation is defined as a unit from one of the CSSS (including local community health centers, residential and long-term care centers, and hospital centers) or a FMG. HCOs targeted by the EHR project will be categorised in strata according to their size, mission, location, and nurses/physicians ratio. $\mathrm{HCO}$ in each stratum will be randomly ordered by an independent biostatistician. HCOs will be contacted and invited to participate in the study according to this random order until $60 \%$ of the $\mathrm{HCO}$ in each stratum have been recruited. If recruitment target of $60 \%$ is achieved in each stratum, a total of 50 $\mathrm{HCO}$ will be recruited. A sample of 50 clusters at the healthcare organisation level is usually considered as sufficient for longitudinal multilevel analyses [79].

In each $\mathrm{HCO}$ cluster, we aim to recruit a minimum of 15 and a maximum of 30 health professionals according to the size of the HCO. The sampling method will be similar to that used for $\mathrm{HCO}$ level. Potential participants in each $\mathrm{HCO}$ will be randomly stratified according to healthcare profession (physician and nurses). Recruitment will take into account the distribution of healthcare professionals in each HCO. We estimate a recruitment rate of $50 \%$ per $\mathrm{HCO}$ which corresponds to that of our preliminary work and to similar studies [25]. When the size of the units varies between organisations, it is suggested to calculate an average group size [80]. Our study sample will thus range between 750 and 1500 healthcare professionals which will be sufficiently powered to test the theoretical model of EHR adoption [81].

\section{Data collection instruments Questionnaire for healthcare organisations}

The HCO questionnaire measures structural and contextual organisational factors and is adapted from the literature $[51,52]$ as well as on our previous work on telehealth adoption in HCO [82]. A preliminary version of this questionnaire was developed, and it will be face-validated by a convenient panel of five healthcare managers from the investigators' networks. This questionnaire will provide information about the organisational level factors that influence EHR adoption.

\section{Questionnaire for healthcare professionals}

Although adoption is considered as the key indicator of the success of EHR implementation by decision makers, no specific measure of this behaviour has been proposed $[83,84]$. It is thus important to provide a consensual measure of EHR adoption that can be used in the healthcare professionals' questionnaire. This cannot be achieved unless the behaviour is carefully defined in terms of its target, action, context, and time, which is known as the TACT approach [58]. Consequently, potential adoption 


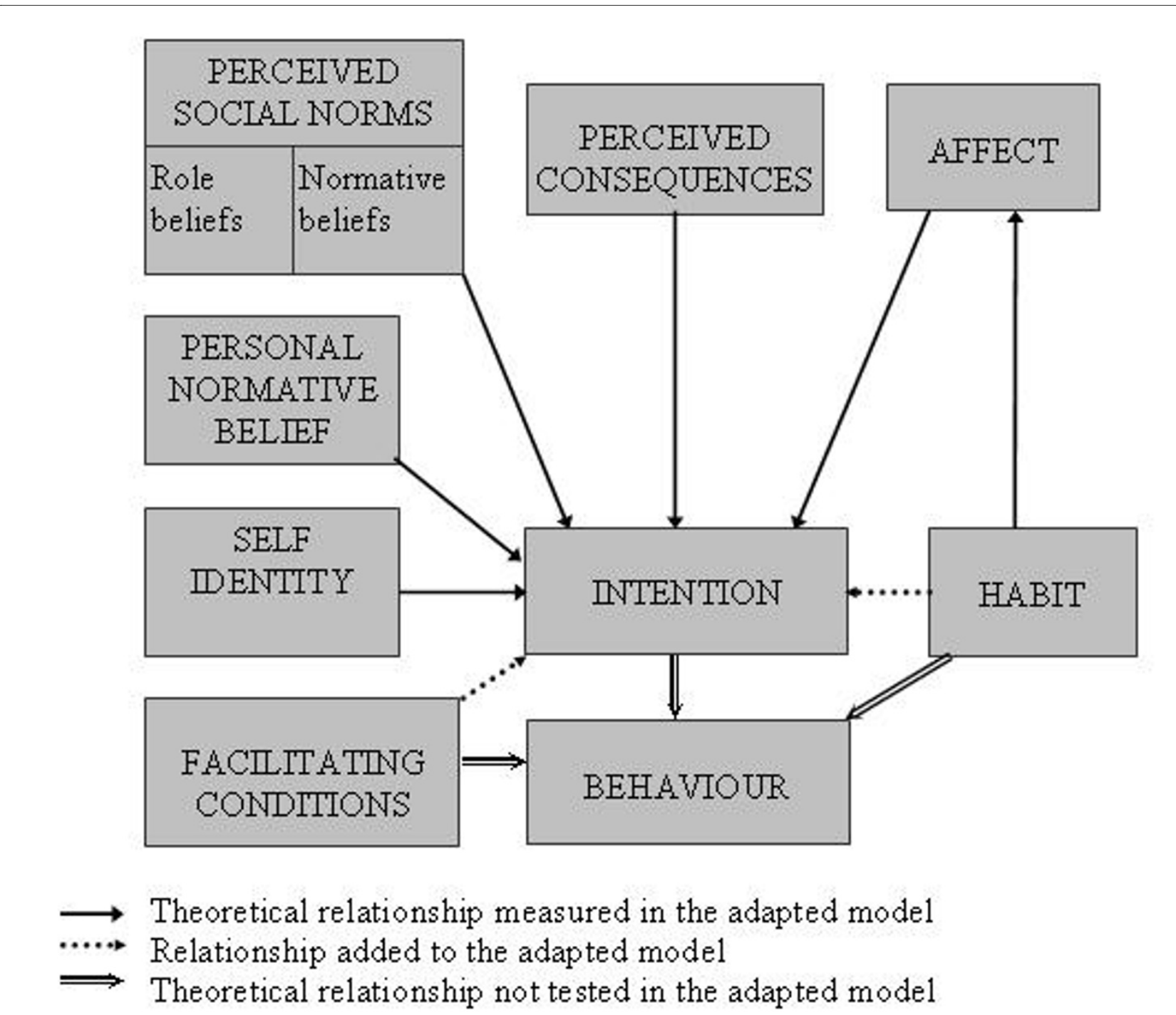

Figure 1 Integrative theoretical framework to assess factors influencing EHR adoption at the individual level. Adapted from the theory of Planned Behaviour [63] and the theory of Interpersonal Behaviour.

behaviours identified from the literature on adoption and diffusion of innovations $[54,85,86]$ will be classified for their relevance to the context of Quebec clinicians through a Delphi study among a panel of experts (see Foy and Bamford [87] for a similar procedure). The Delphi technique allows comparing the degree of written agreement among experts, and it is considered to be a strong methodology for a rigorous consensus of experts on a specific theme [88]. The results of the Delphi study will provide a consensus on the behaviours that will be used to calculate the composite adoption score in the healthcare professionals' questionnaire.

For the development of psychosocial questionnaires, Davidson et al. [89] recommend an etic-emic approach, inspired from the field of anthropology [90]. This method ensures the adaptation of theoretical concepts (the etic component) to the reality of the population under study (the emic component). This approach will be used to develop the questionnaire based on the theoretical constructs from the TIB [73] and the TPB $[63,64]$. To do so, two focus groups will be conducted among convenience samples of physicians and nurses. An experienced research professional trained in anthropology will moderate the focus groups. An open-ended guide will be used to assess participants' beliefs with respect to EHR adoption. Each question corresponds to a construct of the theoretical model. This questionnaire will assess psychosocial determinants of EHR adoption at the individual level and will be matched with HCO questionnaires. 


\section{Data collection}

At the organisational level, the $\mathrm{HCO}$ questionnaire will be administered by telephone at time I to two key informants, representing the managerial (the CEO or equivalent) and the professional (Director of Professional Services or equivalent) decision makers of each of the 50 organisations sampled. Key informants have been widely used in sociology, management, and marketing studies to obtain data on organisational variables [91,92]. Interviewing two respondents from each organisation will increase the convergent validity of data [93] and has been applied in a similar study [52]. The questionnaire will assess a set of structural and contextual characteristics from organisation theories. From our previous experience, we can expect a high response rate with this strategy (100\% in our study of telehealth adoption [82]). Key informants from each participating organisations will be contacted again at time II, which will be between 12 and 18 months after the first data collection step, depending on the pace of EHR implementation in each organisation. The same questions will be used to monitor any important change in the organisation's structure or in its environment, and complementary questions will assess the organisation's progression towards EHR implementation.

At the individual level, individual questionnaires will be distributed at Time I to participating health professionals within each participating organisation. A study code will be assigned to each participant to facilitate follow up. The list of participants' names and codes will be kept confidential. A package containing a letter from the organisation's direction, a leaflet presenting the study, the study questionnaire, a consent form, and a reply envelope will be distributed to participants. At Time II (between 12 and 18 months, depending on the stage of EHR implementation), a second questionnaire will be distributed to the same participants to assess their current use of EHR. The second questionnaire will cover the same items as at Time I, but will also measure the frequency of use of the various components integrated in the EHR (i.e., laboratory tests, prescription database, digital imagery, and electronic clinical note). Because the sample is considered to be relatively stable, we do not anticipate major losses in follow-up. Our conservative sampling also secures a sufficient number of individual respondents by organisational units. Based on the specific adoption behaviours identified through the Delphi study, we will calculate a composite EHR adoption score by summing the score of each adoption behaviour measured, that will correspond to adoption patterns [52] or 'users trajectories' [94]. This categorical variable will be computed according to the trends observed in the global score of the adoption behaviours measured. For example, there could be three categories of adopters, corresponding to low, medium, and high adoption scores.
Furthermore, in order to account for bias inherent to self-reported measures, we will obtain objective utilisation data from the EHR system. Participants' consent will be sought to consult their utilisation of EHR components. The composite adoption score will thus be the dependant variable and we will assess which individual and organisational factors (independent variables) predict EHR adoption by healthcare professionals.

\section{Data analysis}

Descriptive analyses of the data at each level (organisation and individual) will first be conducted to explore the distribution of socio-demographic and theoretical data. Statistics that are used to assess the reliability of individual data aggregated at group level in hierarchical models, such as the intra-class correlation (ICC1 and ICC2), the eta-squared $\left(\eta^{2}\right)$, and the omega-squared $\left(\dot{\omega}^{2}\right)$ will be calculated. Then, the relevance of applying multilevel modelling to our data will be assessed by testing an unconditional or null model in which no predictors are specified. This allows verifying if significant variations in the dependant variable are present across healthcare organisations. If appropriate, a multilevel regression model [95] will be applied to identify organisational and individual determinants of EHR adoption in clinical settings. If no significant variation in EHR adoption is found across HCOs, a one-level path analysis model could be used [96]. If endogenous variables are normally distributed, Ordinary Least Squares (OLS) will be used. If, for specific equations, endogenous variables are not normally distributed, alternative non-linear models will be used. For all those analyses, we will use the MPLUS, version 5.21 [97]. This software allows conducting both path analysis and multilevel analysis with linear and non-linear data, and allows estimating specific indirect effects.

\section{Ethical considerations}

The project has been approved by the ethics committee of the CHUQ Research Centre. Because the study population does not include patients, it is not required to seek ethics approval from other participating healthcare organisations. However, organisations solicited for participating in the project will be informed of the ethical aspects of the research and will receive copies of the research protocol and the ethics approval in order to ensure their informed decision to participate. The questionnaire for healthcare professionals will contain a unique code to identify study participants in order to facilitate follow-up. The list linking nominal information of participants to their study code will be kept in an electronic document protected by a password that will only be known by the principal investigator and the project coordinator. Other questionnaires and research materials will be anonymous. 


\section{Discussion and implications}

This study will provide unique knowledge on the most important factors to consider in the design of strategies for improving EHR adoption by healthcare professionals. As such, it will identify organisational and individual determinants that are key elements to the success of the ambitious interoperable EHR project promoted by the Canadian healthcare system. This project will be the first, to the best of our knowledge, to assess the unique contribution of organisational and individual factors, as well as their interactions, to the successful implementation of EHR. Moreover, the study will imply a wide range of healthcare settings to ensure greater generalisability of the results. These results will be particularly relevant and timely for decision makers who currently face the challenge of implementing EHR in the Canadian healthcare system. This study will apply a novel approach to assess adoption behaviour that is likely to be transferable to other settings. Furthermore, this research addresses some of the most important issues in the field of knowledge transfer and implementation science by proposing a theory-based, multilevel prospective longitudinal study that represents a major contribution to the field [98]. This project is also directly in line with current research priorities of the Canadian healthcare system identified by Listening for Direction III [99]. Finally, the project offers answers to priorities of the Canadian Institutes of Health Research Knowledge Synthesis and Exchange Branch because it will contribute to a better understanding of concepts, theories, and practices that underlie effective knowledge transfer in order to improve the health for Canadians, provide more effective health services and products, and strengthen the healthcare system.

\section{Competing interests}

The authors declare that they have no competing interests.

\section{Authors' contributions}

All authors collectively drafted the research protocol and approved the final manuscript. MPG is its guarantor.

\section{Acknowledgements \\ This study is funded by the Canadian Institutes of Health Research (CIHR; grant \# 200806KAL-187962-KAL-CFBA-111141). MPG has received a New Investigator career grant from the CIHR (grant \# 200609MSH-167016-HAS-CFBA-111141) to support her research program on effective e-health implementation. MO holds a Chercheur Boursier Junior 1 career grant from the Fonds de recherche en santé du Québec (grant \# 16144). GG holds the Canada Research Chair on Behaviour and health from the CIHR.}

\section{Author Details}

1 Research Center of the Centre Hospitalier Universitaire de Québec, Québec, Canada, 2Faculty of Nursing Sciences, Université Laval, Québec, Canada, ${ }^{3}$ Department of Political Science, Université Laval, Québec, Canada and 4Department of Family Medicine, Faculty of Medicine, Université Laval, Québec, Canada

Received: 13 January 2010 Accepted: 23 April 2010

Published: 23 April 2010
References

1. Gunton TA: A Dictionary of information technology and computer science. 2nd edition. Manchester:Oxford: NCC Blackwell; 1993.

2. Alvarez R: The electronic health record: a leap forward in patient safety. HealthcarePapers 2004, 5:33-36. discussion 82-34.

3. Romanow RJ: Building on Values: The Future of Health Care in Canada Final Report. Commission on the Future of Health Care in Canada 2002.

4. Chaudhry B, Wang J, Wu S, Maglione M, Mojica W, Roth E, Morton SC, Shekelle PG: Systematic review: impact of health information technology on quality, efficiency, and costs of medical care. Ann Intern Med 2006, 144:742-752

5. Earnest MA, Ross SE, Wittevrongel L, Moore LA, Lin CT: Use of a patientaccessible electronic medical record in a practice for congestive heart failure: patient and physician experiences. J Am Med Inform Assoc 2004, 11:410-417.

6. Hassol A, Walker JM, Kidder D, Rokita K, Young D, Pierdon S, Deitz D, Kuck S, Ortiz E: Patient experiences and attitudes about access to a patient electronic health care record and linked web messaging. J Am Med Inform Assoc 2004, 11:505-513.

7. Pyper C, Amery J, Watson M, Crook C: Patients' experiences when accessing their on-line electronic patient records in primary care. $\mathrm{Br} \mathrm{J}$ Gen Pract 2004, 54:38-43.

8. Ross SE, Moore LA, Earnest MA, Wittevrongel L, Lin CT: Providing a webbased online medical record with electronic communication capabilities to patients with congestive heart failure: randomized trial. Journal of medical Internet research 2004, 6:e12.

9. Shekelle PG, Morton SC, Keeler EB: Costs and Benefits of Health Information Technology. In Evidence Report/Technology Assessment No. 132. (Prepared by the Southern California Evidence-based Practice Center under Contract No. 290-02-0003.) AHRQ Publication No.06-E006. Agency for Healthcare Research and Quality; 2006.

10. Ueckert F, Goerz M, Ataian M, Tessmann S, Prokosch HU: Empowerment of patients and communication with health care professionals through an electronic health record. Int J Med Inform 2003, 70:99-108.

11. Wilson EV, Lankton NK: Modeling patients' acceptance of providerdelivered e-health. J Am Med Inform Assoc 2004, 11:241-248.

12. Staroselsky M, Volk LA, Tsurikova R, Pizziferri L, Lippincott M, Wald J, Bates DW: Improving electronic health record (EHR) accuracy and increasing compliance with health maintenance clinical guidelines through patient access and input. Int J Med Inform 2006, 75:693-700.

13. Urowitz S, Wiljer D, Apatu E, Eysenbach G, Delenardo C, Harth T, Pai H, Leonard KJ: Is Canada ready for patient accessible electronic health records? A national scan. BMC medical informatics and decision making 2008, 8:33.

14. Beyond Good Intentions: Accelerating the Electronic Health Record in Canada (PDF Version) [http://www.healthcouncilcanada.ca/docs/ papers/2006/infoway.pdf]

15. Delpierre C, Cuzin L, Fillaux J, Alvarez M, Massip P, Lang T: A systematic review of computer-based patient record systems and quality of care: more randomized clinical trials or a broader approach? Int J Qual Health Care 2004, 16:407-416

16. Erstad TL: Analyzing computer based patient records: a review of literature. J Healthc InfManag 2003, 17:51-57.

17. Institute of Medicine: The computer-based patient record: an essential technology for health care. Washington, DC: National Academy Press; 1991.

18. Labkoff SE, Yasnoff WA: A framework for systematic evaluation of health information infrastructure progress in communities. J Biomed Inform 2007, 40:100-105.

19. Simon SR, Kaushal R, Cleary PD, Jenter CA, Volk LA, Poon EG, Williams DH, Orav EJ, Bates DW: Correlates of electronic health record adoption in office practices: a statewide survey. AMIA Annu Symp Proc 2006:1098

20. Hendy J, Fulop N, Reeves BC, Hutchings A, Collin S: Implementing the NHS information technology programme: qualitative study of progress in acute trusts. BMJ 2007, 334:1360

21. Hendy J, Reeves BC, Fulop N, Hutchings A, Masseria C: Challenges to implementing the national programme for information technology (NPfIT): a qualitative study. BMJ 2005, 331:331-336.

22. Pagliari C: Implementing the National Programme for IT: what can we learn from the Scottish experience? Inform Prim Care 2005, 13:105-111. 
23. Currie WL, Guah MW: Conflicting institutional logics: a national programme for IT in the organisational field of healthcare. Journal of Information Technology 2007, 22:235-247.

24. Lapointe L, Rivard S: Getting physicians to accept new information technology: insights from case studies. CMAJ 2006, 174:1573-1578.

25. Simon SR, Kaushal R, Cleary PD, Jenter CA, Volk LA, Poon EG, Orav EJ, Lo $H G$, Williams DH, Bates DW: Correlates of electronic health record adoption in office practices: a statewide survey. J Am Med Inform Assoc 2007, 14:110-117.

26. Anderson JG: Social, ethical and legal barriers to E-health. Int J Med Inform 2007, 76:480-483.

27. Gans D, Kralewski J, Hammons T, Dowd B: Medical groups' adoption of electronic health records and information systems. Health Aff (Millwood) 2005, 24:1323-1333.

28. Miller RH, Sim I: Physicians' use of electronic medical records: barriers and solutions. Health Aff (Millwood) 2004, 23:116-126.

29. Protti D: Comparison of Information Technology in General Practice in 10 Countries. Volume 5. Electronic Healthcare ; 2007:2007.

30. Harris Interactive: Large Differences between Primary Care Practices in the United States, Australia, Canada, Germany, New Zealand, the Netherlands and the United Kingdom. HealthCare News 2007, 7:

31. Lapointe $L$ : L'adoption de systèmes d'information cliniques par les médecins et les infirmières: Une étude des variables individuelles, socio-politiques et organisationnelles. Montreal: Université de Montréal; 1999

32. Berner ES, Detmer DE, Simborg D: Will the wave finally break? A brief view of the adoption of electronic medical records in the United States. J Am Med Inform Assoc 2005, 12:3-7.

33. Lorenzi NM, Riley RT, Blyth AJ, Southon G, Dixon BJ: Antecedents of the people and organizational aspects of medical informatics: review of the literature. J Am Med Inform Assoc 1997, 4:79-93.

34. Burt CW, Sisk JE: Which physicians and practices are using electronic medical records? Health Aff (Millwood) 2005, 24:1334-1343.

35. Ford EW, Menachemi N, Phillips MT: Predicting the adoption of electronic health records by physicians: when will health care be paperless? J Am Med Inform Assoc 2006, 13:106-112.

36. Loomis GA, Ries JS, Saywell RM Jr, Thakker NR: If electronic medical records are so great, why aren't family physicians using them? J Fam Pract 2002, 51:636-641.

37. Menachemi N: Barriers to ambulatory EHR: who are 'imminent adopters' and how do they differ from other physicians? Inform Prim Care 2006, 14:101-108.

38. Dillon TW, Blankenship R, Crews T Jr: Nursing attitudes and images of electronic patient record systems. Comput Inform Nurs 2005, 23:139-145

39. Geibert RC: Using diffusion of innovation concepts to enhance implementation of an electronic health record to support evidencebased practice. Nurs Adm Q 2006, 30:203-210

40. Overhage JM, Evans L, Marchibroda J: Communities' readiness for health information exchange: the National Landscape in 2004. J Am Med Inform Assoc 2005, 12:107-112.

41. Simon JS, Rundall TG, Shortell SM: Drivers of electronic medical record adoption among medical groups. Jt Comm J Qual Patient Saf 2005 31:631-639.

42. Snyder-Halpern R, Fields WV: Measuring hospital readiness for information technology (IT) innovation: A multisite study of the Organizational Information Technology Innovation Readiness Scale. J Nurs Meas 2006, 14:45-55.

43. Lapointe L, Rivard S: L'implantation d'un système d'information clinique. ASAC Conference; St-John (N-B) 1999.

44. Ferlie EB, Shortell SM: Improving the quality of health care in the United Kingdom and the United States: a framework for change. Milbank $Q$ 2001, 79:281-315

45. Eccles M, Grimshaw J, Walker A, Johnston M, Pitts N: Changing the behavior of healthcare professionals: the use of theory in promoting the uptake of research findings. J Clin Epidemio/ 2005, 58:107-112.

46. Mintzberg $\mathrm{H}$ : The structuring of organizations. Englewood Cliffs: $\mathrm{NJ}$ : Prentice Hall; 1979.
47. DiMaggio $P$, Powell W: The iron cage revisited: Institutional isomorphism and collective rationality in organizational fields. American Sociological Review 1983, 48:147-160.

48. Meyer JW, Rowan B: Institutionalized organizations: Formal structures as myth and ceremony. Am J Sociol 1977, 83:340-363.

49. Scott RW: Lords of the dance: Professionals as institutional agents. Organization Studies 2008, 29:219-238.

50. Anderson N, De Dreu CKW, Nijstad BA: The routinization of innovation research: a constructively critical review of the state-of-the-science. Journal of Organizational Behavior 2004, 25:147-173.

51. Damanpour F: Organizational innovation: A meta-analysis of effects of determinants and moderators. Acad Manage J 1991, 34:555-590.

52. Kimberly JR, Evanisko MJ: Organizational innovation: the influence of individual, organizational, and contextual factors on hospital adoption of technological and administrative innovations. Acad Manage J 1981, 24:689-713

53. Lansisalmi H, Kivimaki M, Aalto $P$, Ruoranen R: Innovation in healthcare: a systematic review of recent research. Nurs Sci Q 2006, 19:66-72.

54. Rogers EM: The Diffusion of innovations. 4th edition. New York: The Free Press; 1995.

55. Berwick DM: Disseminating innovations in health care. JAMA 2003, 289:1969-1975

56. Chau PYK, Tam KY: Factors affecting the adoption of open systems: an exploratory study. MIS Quarterly 1997, 21:1-24.

57. Davis FD: Perceived usefulness, perceived ease of use, and user acceptance of information technology. MIS Quarterly 1989, 13:319-340.

58. Fishbein M, Azjen I: Belief, attitude, intentions and behavior: an introduction to theory and research. Boston: Addison-Westley; 1975

59. Venkatesh V, Morris MG, Davis GB, Davis FD: User acceptance of information technology: Toward a unified view. MIS Quarterly 2003, 27:425-478

60. Croteau AM, Vieru Di: Telemedicine adoption by different groups of physicians. In 35th Hawaii International Conference on System Sciences; Maui IEEE Computer Society; 2002

61. Hu PJ, Chau PYK, Liu Sheng OR, Yan Tam K: Examining the technology acceptance model using physician acceptance of telemedicine technology. Journal of Management Information Systems 1999, 16:91-112.

62. Van Schaik P, Flynn D, Van Wersch A, Douglass A, Cann P: The acceptance of a computerised decision-support system in primary care: a preliminary investigation. Behaviour \& Information Technology 2004, 23:321-326

63. Ajzen I: From intentions to actions: A theory of planned behavior. In Action-control: from cognition to behavior Edited by: Kulh J, Beckman J. Heildelberg: Springer; 1985:11-39.

64. Ajzen I: The theory of planned behavior. Organ Behav Hum Decis Process 1991, 50:179-211.

65. Armitage CJ, Conner M: Efficacy of the Theory of Planned Behaviour: a meta-analytic review. Br J Soc Psychol 2001, 40:471-499.

66. Godin G, Naccache H, Morel S, Ebacher MF: Determinants of nurses' adherence to universal precautions for venipunctures. Am J Infect Control 2000, 28:359-364.

67. Légaré F, Godin G, Ringa V, Dodin S, Turcot L, Norton J: Variation in the psychosocial determinants of the intention to prescribe hormone therapy prior to the release of the Women's Health Initiative trial: a survey of general practitioners and gynaecologists in France and Quebec. BMC medical informatics and decision making 2005, 5:31.

68. Levin PF: Test of the Fishbein and Ajzen models as predictors of health care workers' glove use. Res Nurs Health 1999, 22:295-307.

69. Walker $A E$, Johnston $M$, et al:: When do clinicians follow guidelines? Using the theory of planned behaviour to predict intentions to prescribe prophylaxis for patients at risk of deep vein thrombosis. $J$ Epidemiol Community Health 1998, 52:676.

70. Godin G, Belanger-Gravel A, Eccles M, Grimshaw J: Healthcare professionals' intentions and behaviours: A systematic review of studies based on social cognitive theories. Implement Sci 2008, 3:36

71. Webb TL, Sheeran P: Does changing behavioral intentions engende behavior change? A meta-analysis of the experimental evidence. Psychol Bull 2006, 132:249-268. 
72. Eccles MP, Hrisos S, Francis J, Kaner EF, Dickinson HO, Beyer F, Johnston M: Do self- reported intentions predict clinicians' behaviour: a systematic review. Implement Sci 2006, 1:28.

73. Triandis HC: Values, attitudes and interpersonal behavior. In Nebraska Symposium on Motivation 1979: Beliefs, attitudes and values Edited by: Page MM. University of Nebraska Press: Lincoln; 1980.

74. Facione NC: The Triandis model for the study of health and illness behavior: a social behavior theory with sensitivity to diversity. ANS Adv Nurs Sci 1993, 15:49-58.

75. Gagnon MP, Godin G, Gagne C, Fortin JP, Lamothe L, Reinharz D, Cloutier A: An adaptation of the theory of interpersonal behaviour to the study of telemedicine adoption by physicians. Int J Med Inform 2003, 71:103-115.

76. Gagnon MP, Legare F, Labrecque M, Fremont P, Cauchon M, Desmartis M: Perceived barriers to completing an e-learning program on evidencebased medicine. Inform Prim Care 2007, 15:83-91.

77. Gagnon MP, Sanchez E, Pons JM: From recommendation to action: psychosocial factors influencing physician intention to use Health Technology Assessment (HTA) recommendations. Implement Sci 2006, 1:8.

78. Goldstein HI: Multilevel statistical models. 3rd edition. London: Edward Arnold; 2003.

79. Maas CJM, Hox JJ: Sufficient Sample Sizes for Multilevel Modeling. Methodology: European Journal of Research Methods for the Behavioral and Social Sciences 2005, 1:85-91.

80. Tinsley HE, Weise DJ: Interrater reliability and agreement of subjective judgement. Journal of Counseling Psychology 1975, 22:358-376.

81. Cohen J: Statistical power analysis for the behavioral sciences. 2nd edition. Hillsdale, N.J.: Lawrence Erlbaum Associates Publishers; 1988.

82. Gagnon MP, Lamothe L, Fortin JP, Cloutier A, Godin G, Gagne C, Reinharz D: Telehealth adoption in hospitals: an organisational perspective. J Health Organ Manag 2005, 19:32-56.

83. Corporate Business Plan 2007-08 [http://www2.infoway-inforoute.ca/ Documents/Business\%20Plan 2007-08 EN.pdf]

84. Gouvernement du Québec: Avis d'intention du ministre de la Santé et des Services sociaux sur les conditions de mise en oeuvre du projet pilote du Dossier de santé du Québec. 2008.

85. Jbilou J, Amara N, Landry R: Research-based-decision-making in Canadian health organizations: a behavioural approach. J Med Syst 2007, 31:185-196.

86. Landry R, Amara N, Lamari M: Utilization of Social Science Research Knowledge in Canada. Res Pol 2001, 30:333-349.

87. Foy R, Bamford C, Francis JJ, Johnston M, Lecouturier J, Eccles M, Steen N, Grimshaw J: Which factors explain variation in intention to disclose a diagnosis of dementia? A theory-based survey of mental health professionals. Implement Sci 2007, 2:31.

88. Okoli C, Pawlowski SD: The Delphi method as a research tool: an example, design considerations and applications. Inform Manage 2004, 42:15-29.

89. Davidson AR, Jaccard JJ, Triandis HC, Morales ML, Diaz-Guerrero R: Crosscultural model testing: Toward a solution of the etic-emic dilemma. International Journal of Psychology 1976, 11:1-13.

90. Pelto PJ: Anthropological Research: The structure of inquiry. New York: Harper Row; 1970

91. Anderson JC: An approach for confirmatory measurement and structural equation modeling of organizational properties. Management Science 1987, 33:525-541.

92. Campbell D: The informant in quantitative research. American Journal of Sociology 1955, 60:339-342.

93. Venkatraman N, Grant JH: Construct measurement in organizational strategy research: a critique and proposal. The Academy of Management Review 1986, 11:71-87.

94. Zheng K, Padman R, Johnson MP, Diamond HS: Understanding technology adoption in clinical care: clinician adoption behavior of a point-of-care reminder system. Int J Med Inform 2005, 74:535-543.

95. Raudenbush SW, Liu X: Statistical power and optimal design for multisite randomized trials. Psychol Methods 2000, 5:199-213.

96. Adewale AJ, Hayduk L, Estabrooks CA, Cummings GG, Midodzi WK Derksen L: Understanding hierarchical linear models: applications in nursing research. Nurs Res 2007, 56:540-46.

97. Muthén LK, Muthén BO: Mplus Users Guide. Fifth edition. Los Angeles, C.A: Muthén and Muthén; 2007.
98. Titler MG, Everett LQ, Adams S: Implications for implementation science. Nurs Res 2007, 56:S53-59.

99. Law S, Flood C, Gagnon D: Listening for Direction III partners. Listening for Direction: A National Consultation on health services and policy issues. Canadian Health Services Research Foundation. Canadian Institutes of Health Research, Institute of Health Services and Policy Research; 2008.

doi: $10.1186 / 1748-5908-5-30$

Cite this article as: Gagnon et al., Multi-level analysis of electronic health record adoption by health care professionals: A study protocol Implementation Science 2010, 5:30

\section{Submit your next manuscript to BioMed Central and take full advantage of:}

- Convenient online submission

- Thorough peer review

- No space constraints or color figure charges

- Immediate publication on acceptance

- Inclusion in PubMed, CAS, Scopus and Google Scholar

- Research which is freely available for redistribution

Submit your manuscript at www.biomedcentral.com/submit
C Biomed Central 